Article

\title{
Task-Oriented and Relationship-Building Communications between Air Traffic Controllers and Pilots
}

\author{
Inwon Kang ${ }^{1}$, Shin Han $^{2}$ and Jiwon Lee ${ }^{1, *}$ \\ 1 Department of International Business and Trade, Kyung Hee University, Seoul 02447, Korea; \\ iwkang@khu.ac.kr \\ 2 Division of Behavioral \& Organizational Sciences, Claremont Graduate University, \\ Claremont, CA 91711, USA; shin.han@cgu.edu \\ * Correspondence: yemannuer@khu.ac.kr; Tel.:+82-2-961-9182
}

Received: 3 September 2017; Accepted: 25 September 2017; Published: 29 September 2017

\begin{abstract}
By questioning the lopsided attention on task-oriented factors in air traffic controller-pilot communication, the current study places an equal weighting on both task-oriented and relationship-building communications, and investigates how each type of communication influences sustainable performance in airline operation team. Results show that both task-oriented and relationship-building communications in terms of sustainability of team process predicted greater communication satisfaction at work. Also, both task interdependence and shared leadershipinfluenced both types of air traffic controller-pilot communication. However, only relationship-building communication had a direct influence on perceived work performance whereas task-oriented communication had not. Along with task-oriented factors, this study raises the relationship-oriented factors as important resources for the sustainable team performance in airline industry.
\end{abstract}

Keywords: team performance; sustainable performance; task-oriented communication; relationship-building communication; structural equation modeling

\section{Introduction}

In everyday communication, we strive to explicitly transfer information to listeners and correctly receive information from speakers. These efforts aid in avoiding the possibility of miscommunications. However, every communication contains ambiguity and miscommunication, making every discourse potentially problematic [1]. Therefore, much of what is said is neither completely true, nor completely false.

If miscommunication is unavoidable, then our communication task should be to minimize miscommunication in all circumstances [1,2], because miscommunication can lead to unwanted consequences [3]. In teamwork, when communicators are interdependent in achieving certain tasks or jobs, collaborative performance becomes heavily dependent upon communication [4]. Considering the chances of miscommunication, the significance of its consequence, and the interdependence of teamwork, communication between pilots and air traffic control could likely generate frequent miscommunications. Miscommunication of this type can lead to deadly air disasters that have the ability to destroy a region or country's tourist industry [5,6].

In improving air traffic controller (ATC)-pilot team communication, studies report that both technical and relational factors are important. Nevertheless, existing research on ATC-pilot team communication emphasizes mostly task-related technical factors, such as contents, or medium communication $[7,8]$. 
Although technical factors in communication are important at work, a large portion of communication in the workplace is informal or social. These informal communications may not be directly related to work tasks, but the role of these informal communications can go beyond relationship-building, such that they also support work-related tasks [9]. While nontechnical human factors are recently considered to be important in air traffic management, informal communications and relational factors in ATC-pilot teamwork are still under-emphasized. Therefore, in the current study, we focus on the relational factors and examine how they affect work performance in controller-pilot interaction. Especially, in terms of ATC-pilot team communications, we invest them into task-oriented and relationship-building and examine how each type is affected by relational factors and sustainable performance in controller-pilot teams.

In measuring performance in airline operations, many studies have focused on quantitative outcomes. In ATC-pilot teamwork, team performance is usually measured by quantitative data, such as the frequency or proportion of missing acknowledgements, incorrect/partial readbacks, or missing call signs [10]. Such quantitative measures are important in ATC-pilot team performance, but they prove difficult in capturing issues mid-process because the focus has been on quantifiable results and final outcomes.

As a supplement and an alternative to quantifiable concrete measures, team members' perception about sustainable performance not only captures the results and outcomes, but also reflects social and interpersonal issues existing in the teamwork process [11]. To capture the procedural issues, especially related to sustainable performance management, we use perceived performance measures from ATC and pilots to reflect problems and issues in the team working. We believe that adding relational factors and sustainable team performance measures in ATC-pilot teamwork expand our understanding in the domain of airline service.

\section{Difficulties in Air Traffic Controller-Pilot Communication}

It is reported that a large number of plane accident happen because of miscommunication and language issues [12] and that they amount to $37 \%$ of all airplane accidents [13]. To avoid accidents and successfully perform the landing operation and other given tasks on schedule, the ATC-pilot team is required to exchange accurate communications to successively complete collaborative tasks $[5,6]$.

Although correct and clear communication is essential in ATC-pilot teamwork, difficulties exist for ACT-pilot teams to maintain correct communication. First, they use radio-communication which makes it difficult to have clear communication all the time. Although it is reported that there is no significant difference between face-to-face and voice media communication in problem solving and information transmission [14], multiple interactions between a single controller and many pilots limit each ACT to spend a very short time with a single airplane, possibly leading to congested frequencies and blocked transmissions [10]. Second, for the pilots, long messages from the ACTs appear to overload their working memory, resulting in more incorrect or partial readbacks, as well as more message repeat requests [8]. All these factors lead to missing acknowledgements, incorrect/partial readbacks, or missing call signs [10]. In sum, difficulties in the work environment keep ACT-pilot teams from exchanging clear communications all the time.

\section{Task-Oriented and Relationship-Building Communications}

According to Habermas [15], two types of communication exist between agents engaged in speech acts. First, when the purpose of communication is to achieve the speaker's goal by asking and making the listener do certain behaviors, the communication is oriented toward success, leading communicators to instrumentalize one another as a means of achieving success. In a customer satisfaction study by Froehle [16], this type of communication is termed task-oriented communication, which is aimed at achieving goals, solving problems, and making decisions [17].

Another type of communication is oriented toward understanding the other party [18]. Here, it becomes more important for the communicators to understand each other, 
rather than be successful in performing certain tasks. Thus, this type of communication is "person-oriented" [17] and "relationship-oriented" [18]. Froehl [16] coined this type of communication relationship-building communication.

In ACT-pilot teamwork, most studies have focused on how the content of the communication is clearly transferred between ACTs and pilots, i.e., task-oriented communicaion, or how environmental and human factors affect their communication $[10,19,20]$. While their communication is mostly task-oriented, it is also possible that there are elements of relationship-building communication in their dialogues. In aviation psychology, studies have examined the influence of 'attitudes' in performance [10]. Because performance usually takes place in teams, and each member takes on a different role creating interdepdence, members will perceive the 'attitudes' of other members, from communication practices. Therefore, to investigate the effect of communication in ACT-pilot teamwork, not only task-oriented but also relationship-building communication needs to be considered.

\section{Antecedents of Task-Oriented and Relationship-Building Communications in Air Traffic Controller-Pilot Interactions}

\subsection{Relational Factors in Communication in Aviation}

In airline operation service, focus has mainly been placed on the technical factors in explaining and reducing miscommunications, incidents and accidents $[8,10]$. In addition, nontechnical human factors have been considered as important in explaining and decreasing flight miscommunications [20]. There are not many approaches about the relationship between relational factors and miscommunications in flight. Only a small number of studies have focused on the effect of social and relational factors in airline operation [21,22].

Outside of airline operation, it has been reported that relational factors such as task interdependence and shared leadership affect workplace communication [23,24]. In airplane operation, every ACT-pilot team is highly interdependent such that each party cannot perform landing and other tasks individually. Such high interdependency requires high interpersonal involvement among team members. Because both the interdependency and mutual involvement imply a relationship between ACT-pilot teams, one can also expect relational factors to relate to communication in ACT-pilot teamwork.

\subsection{Task Interdependence}

Among the various relational factors at work, task interdependence is an important communication factor. In organizational literature, task interdependence is defined as the degree of reliance among group members on others to perform their tasks effectively given the design of their jobs [25]. Studies have shown that task interdependence increases group member communication and helping and information sharing [26,27]. In a highly interdependent situation, because each group member must rely on others to achieve pre-determined goals, it seems natural for group members to increase communication in order to exchange expertise and information to achieve the desired outcomes [27-29].

Although previous studies found positive influence from task interdependence on communication and sustainable performance, they did not distinguish task-oriented from relationship-building communication. Considering the nature of task interdependence such that it implies the degree to which team members will interact and depend upon each other to attain their goals [29], it is expected that task interdependence will exert greater influence on task-oriented communication than relationship-building communication. Therefore, we predict:

Hypothesis 1 (H1). Task interdependence predicts both task-oriented and relationship-building communication. However, the association between task interdependence and task-oriented communication is greater than the association between task interdependence and relationship-building communication. 
Hypothesis 2 (H2). Task interdependence predicts team performance.

\subsection{Shared Leadership}

Another factor that influences communication in teamwork is shared leadership. According to Pearce and Conger [30], shared leadership is "a dynamic, interactive influence process among individuals in groups for which the objective is to lead one another to the achievement of group or organizational goals or both" [30]. A major difference between shared and traditional vertical leadership is that while the latter involves mostly hierarchical influence processes, the former includes both hierarchical and lateral influence processes. Particularly in cross-functional teams which lack hierarchical authority, or have a formally appointed leader who is highly dependent on the team members' unique knowledge, skills, and backgrounds, shared leadership may be a powerful and potentially successful form of leadership [18,31]. ACT-pilot teams are cross-functional, thus we expect that shared leadership will lead to better communication and performance. Moreover, because better communication is likely to lead to higher communication satisfaction, we can also expect shared leadership to have the same result.

Considering the effects of shared leadership on the two previously mentioned types of communication, previous research shows that in terms of 'achievement of goals', shared leadership is also associated with relationship building [32]. Also, Perry, Pearce and Sims [33] state that shared leadership in teams leads to both affective responses as well as behavioral responses. Since shared leadership is associated with behavioral responses and affective responses, we can expect that shared leadership influences communications related to both task and relationship-building.

Although most studies on shared leadership examine the relationship between shared leadership and performance efficiency, it has been suggested that there is "a shift toward conceptualizing leadership less as the behaviors and characteristics of individuals and more as a social process that is embedded in a context of team dynamics and social interaction" [31] (p. 311). According to Carson, Tesluk and Marrone [34], one of the antecedents for shared leadership is social support, which is defined as "team members' efforts to provide emotional and psychological strength to one another". Social support maintains and develops a team by providing "interpersonal glue" that helps build a strong internal social network [35]. Since social support predicts shared leadership, it is expected that shared leadership positively affects communication committed to social support and relationship-building. Based on this, we expect that shared leadership in ACT-pilot teams will have a higher level of influence on social interaction than task-related behaviors. Therefore, we predict:

Hypothesis 3 (H3). Shared leadership predicts both task-oriented and relationship-building communication. However, the association between shared leadership and relationship-building communication is greater than the association between shared leadership and task-oriented communication.

Hypothesis 4 (H4). Shared leadership predicts team performance.

Hypothesis 5 (H5). Shared leadership predicts communication satisfaction.

In terms of the relationship between shared leadership and task interdependence, previous research has demonstrated that teams outperform individuals on tasks involving greater integration and interconnectedness [36]. Thus, in order to take full advantage of team members' competencies, the need for shared leadership is high when the tasks of the individuals are entirely interdependent [30]. Therefore, we predict:

Hypothesis 6 (H6). Task interdependence predicts shared leadership.

Considering the precursors of task-oriented and relationship-building communication, we suggest that relational factors such as task interdependence and shared leadership influence ACT-pilot communication. 


\section{Relationship between Task-Oriented and Relationship-Building Communication in Air Traffic Controller-Pilot Teams}

Previous researchers are not aware clearly examining the relationship between task-oriented and relationship-building communication. However, we can infer a relationship between task-oriented and relationship-building communication in ACT-pilot interaction from existing studies. Jarvenpaa and Leidner [18] found that task-oriented communication correlates with trust in virtual teams and social communication is related with trust in virtually collaborating teams. The teams with low initial exchange shared few social messages during the first two weeks, and then gradually began to interact to construct relationship-building communication. Therefore, we can expect not only relationship building communication between team members to take longer than task-oriented communication, but also task-oriented communication to positively affect relationship-building communication. In this sense, we predict:

Hypothesis 7 (H7). Task-oriented communication predicts relationship-building communication.

\section{Outcomes of Task-Oriented and Relationship-Building Communications in Air Traffic Controller-Pilot Teams}

\subsection{Communication Satisfaction}

Once ACTs and pilots have successful communication, it will naturally lead to communication satisfaction. Communication satisfaction refers to "the affective response to the fulfillment of expectation-type standards" in message exchange processes and "symbolizes an enjoyable, fulfilling experience" [37]. In organizational settings, it has been defined as an individual's satisfaction with communication in interpersonal, group, or organizational contexts e.g., [38].

Although previous studies examined various antecedents of communication satisfaction, it is difficult to find the study that directly investigated the effects of task-oriented and relationship-building communication on communication satisfaction. Communication satisfaction seems to be more related with task-oriented communication than relationship-building communication because task-oriented communication is immediately rewarded by task performance. Also, since people are more task-oriented in remote communication than face-to-face communication [39], it is expected that compared to relationship-building communication, task-oriented communication shows a larger influence on communication satisfaction. Therefore, we predict:

Hypothesis 8 (H8). Communication satisfaction is associated with task-oriented and relationship-building communication. However, the association between communication satisfaction and task-oriented communication is greater than the association between communication satisfaction and relationship-building communication.

\subsection{Team Performance}

Successful communication influences collaboration and overall team performance $[40,41]$. Along with the two main variables of task-oriented and relationship-building communications, the antecedents and consequences of these communications (interdependence, shared leadership, and communication satisfaction) all boil down to team performance. The objective of forming a team or an organization is to achieve a common goal through team members' collaborative capabilities [41-44]. The capabilities of each team member collectively result in team performance through the aforementioned variables. Therefore, we expect both task-oriented and relationship-building communication to be associated with sustainable performance of airline operation team.

Although it is difficult to find studies measuring the effects of task-oriented and relationship-building communication on team performance, there are few research findings that group cohesiveness $[45,46]$ are positively associated with group performance. Cohesiveness refers to the degree to which group members bond to one another and to the group as a whole. 
Moreover, the bonds are not to develop spontaneously [45,46]. Because of this characteristic, this paper expects relationship-building communication to have greater impact on team performance. Although task-oriented communication can affect performance, it will take an indirect route rather than a direct route assuming team performance is primarily dependent on cohesiveness. Therefore, we predict:

Hypothesis 9 (H9). Team performance is associated with both task-oriented and relationship-building communication. However, the association between team performance and relationship-building communication is greater than the association between team performance and task-oriented communication.

Lastly, in addition to successful task-oriented and relationship-building communication, communication satisfaction is expected to have positive association with team performance. Studies have found there is a strong relationship between communication satisfaction and job performance e.g., [37]. We expect similar results in ACT-pilot interaction and thus predict:

Hypothesis 10 (H10). Communication satisfaction predicts team performance.

So far, we have explained the two types of communication in ACT-pilot interaction and their antecedents and outcomes (see Figure 1). In this paper, we examine ACT-pilot teamwork and illustrate the direct and indirect relationships of the reviewed variables on team performance.

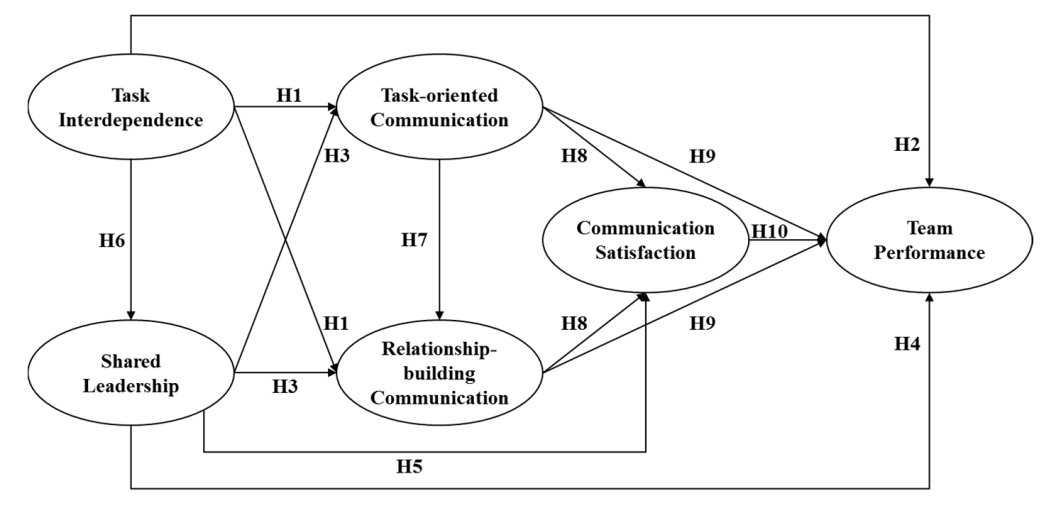

Figure 1. Research model.

\section{Research Method}

\subsection{Sampling and Survey Procedure}

To test the proposed research model, ATCs and pilots were surveyed. This was conducted on both ATCs stationed at Incheon International Airport (IIA) and pilots who disembarked at IIA. In order to represent the multinational nature of their communication, the ATCs are local South Koreans while the pilots are from international airlines on stopover in IIA.

The survey was developed in English. A questionnaire was designed based on the research model (see Figure 1), in which items to measure six constructs were presented. A literature search identified relevant items for each construct. Task interdependence was adopted from Nielsen et al. [11]. Shared leadership was adopted from Hoch, Pearce and Welzel [47]. From the customer satisfaction questionnaire by Froehle [16], both task-oriented and relationship-building communication items were adopted. Communication satisfaction was adopted from Pornsakulvanich [38].

In airline operations, team performance is usually measured by quantitative data. However, the quantitative data may not be directly associated with the variables we are using for this study. Instead, we modified the qualitative assessment of airline service by Sun et al. [41] that is used for pilot and ACT evaluation, and created a perceived team performance measurement item. In addition, we developed a perceived quantitative performance measure. For the details about the items for each construct, refer to Table 1 . 
Table 1. Measurement items.

\begin{tabular}{|c|c|c|}
\hline Variables & Measurement Items & Sources \\
\hline Task Interdependence & $\begin{array}{l}\text { In a controller-pilot team, I have to obtain information and advice from my partner in order to complete the joined task. } \\
\text { In a controller-pilot team, I depend on my partner for the completion of the joined task. } \\
\text { In a controller-pilot team, I have to work closely with my partner to do the joined task properly. } \\
\text { In a controller-pilot team, my work is not complete until everyone has done his or her part. } \\
\text {-DELETED }\end{array}$ & Nielsen et al. [11] \\
\hline Shared Leadership & $\begin{array}{l}\text { In a controller-pilot team, I coordinate my efforts with my partner to achieve assigned goals. } \\
\text { In a controller-pilot team, collaboration with my partner works well. } \\
\text { In a controller-pilot team, all team members share responsibilities for the task. }\end{array}$ & Hoch et al. [47] \\
\hline Task-oriented Communication & $\begin{array}{l}\text { I believe having much general aviation knowledge is important for effective controller-pilot communication (knowledge). } \\
\text { I believe being thorough in providing information is important for effective controller-pilot communication (thoroughness). } \\
\text { I believe being prepared about each other's needs is important for effective controller-pilot communication (preparedness)-DELETED }\end{array}$ & Froehle [16] \\
\hline Relationship-building Communication & $\begin{array}{l}\text { I believe being courteous to each other is important for effective controller-pilot communication (courtesy). } \\
\text { I believe being professional on the job is important for effective controller-pilot communication (professionalism). } \\
\text { I believe attentive listening to each other is important for effective controller-pilot communication (attentiveness). }\end{array}$ & Froehle [16] \\
\hline Communication Satisfaction & $\begin{array}{l}\text { In a controller-pilot team, our conversation flowed smoothly. } \\
\text { In a controller-pilot team, we all were attentive to each other's comments. } \\
\text { In a controller-pilot team, I am satisfied with the communication with the partner overall. }\end{array}$ & Pornsakulvanich [38] \\
\hline Team Performance & $\begin{array}{l}\text { In a controller-pilot team, collaboration with the partner resulted in improvement of teamwork. } \\
\text { In a controller-pilot team, sustainability of team process with the partner resulted in lowered delay/incident/accident rate. } \\
\text { In a controller-pilot team, collaboration with the partner allowed prompt project completion. } \\
\text {-DELETED }\end{array}$ & Sun et al. [41] \\
\hline
\end{tabular}


The responses were collected from 222 pilots and 96 ACTs, but 38 responses were excluded due to unanswered items, leaving 280 responses in the final sample test. The responses were not collected from pilot-ACT pairs but a separate set of pilots and ACTs. Concerning the possibility of group difference between pilots and ACTs, $t$-tests were conducted for the constructs. The results from the $t$-test showed no significant differences between ACT and pilot group with variances treated as equal from the result of Levene's Test for Equality of Variances. As no significant differences were observed for the constructs, the data for the main analysis were pooled together.

The reliability of each construct measured by Cronbach's alpha values for all constructs was acceptable based on the guidelines introduced by Hair et al. [48], with the lowest measuring 766 . The convergent validity and uni-dimensionality of each construct were verified with a principal components factor analysis showing a single Eigenvalue above 1 for each construct. All items loaded as predicted, except for three items on task interdependence, task-oriented communication, and team performance dropped respectively, because of low item-to-total correlations and factor loadings.

As this study uses self-report survey measures, it is likely for common method variance bias to occur. To prevent potential biases, Harman's single factor analysis was employed as suggested in Podsakoff et al. [49]. The percentage of explained variance of a single-factor model was 12.55 which did not exceed the acceptable percentage of 25 percent, concluding that the common method variance bias was unobserved.

Among the 280 responses, $201(72 \%)$ were pilot, and $79(28 \%)$ were air traffic controller. Regarding the type of pilot's carrier, 93 (46\%) respondents were affiliated with Korean Air, $64(32 \%)$ with Asiana Airlines, and others 44 (22\%). Among the 79 air traffic controllers, 46 (58\%) were ACC controllers affiliated to Ministry of Land, Infrastructure and Transport, and 33 (42\%) were ramp controllers of Incheon International Airport Corporation. Of the respondents, $13(4 \%)$ were in their twenties, $73(26 \%)$ in their thirties, $66(24 \%)$ in their forties, and $128(46 \%)$ over fifty.

\subsection{Measure Validation}

The proposed research model in this study is composed of six constructs with interconnected causal paths requiring Structural Equation Modeling (SEM) [48]. Consistent with Hair et al. [48], convergent validity of Confirmatory Factor Analysis (CFA) results should be supported by item reliability, construct (composite) reliability, and average variance extracted (AVE). From Table 2, values for all the standardized factor loadings of items are statistically significant, assuring item reliability. Composite reliability values, which should be greater than 0.70 [48], range from 0.763 to 0.894 .

AVE, which should be above 0.50 , measures the amount of variance explained by the construct [48] indicating high reliability and validity. Since inter-correlations between constructs are relatively high, a common method bias may exist. In order to avoid this, discriminant validity tests were performed in accordance with Hair et al. [48]. Table 2 shows that AVE ranged from 0.616 to 0.738 , which are greater than the squared correlations between the six constructs falling between 0.13 and 0.50 (see Table 3 ). Therefore, the six constructs identified through the CFA approach are confirmed to possess enough convergent and discriminant validity for further SEM analysis. 
Table 2. Measurement properties of variables.

\begin{tabular}{|c|c|c|c|c|c|c|c|}
\hline Construct & Items & Factor Loading & Standard Errors & Standardized Loading & $t$-Value & Composite Reliability & Average Variance Extracted \\
\hline \multirow{3}{*}{ Task Interdependence } & TI1 & 1.000 & - & 0.706 & - & \multirow{3}{*}{0.863} & \multirow{3}{*}{0.680} \\
\hline & TI2 & 1.229 & 0.094 & 0.867 & 13.106 ** & & \\
\hline & TI3 & 1.257 & 0.095 & 0.888 & $13.244^{* *}$ & & \\
\hline \multirow{2}{*}{ Shared Leadership } & SL1 & 1.000 & - & 0.842 & - & \multirow{2}{*}{0.869} & \multirow{2}{*}{0.692} \\
\hline & SL3 & 0.830 & 0.064 & 0.699 & $13.046^{* *}$ & & \\
\hline \multirow[b]{2}{*}{ Task-oriented Communication } & TC1 & 1.000 & - & 0.753 & - & \multirow[b]{2}{*}{0.763} & \multirow[b]{2}{*}{0.616} \\
\hline & TC2 & 1.083 & 0.097 & 0.816 & $11.156^{* *}$ & & \\
\hline \multirow{2}{*}{ Relationship-building Communication } & $R C 1$ & 1.00 & - & 0.788 & - & \multirow{2}{*}{0.894} & \multirow{2}{*}{0.738} \\
\hline & $R C 3$ & 1.107 & 0.068 & 0.872 & $16.167^{* *}$ & & \\
\hline \multirow{3}{*}{ Communication Satisfaction } & CS1 & 1.00 & - & 0.832 & - & \multirow{3}{*}{0.891} & \multirow{3}{*}{0.732} \\
\hline & CS2 & 1.102 & 0.059 & 0.917 & 18.523 ** & & \\
\hline & CS3 & 0.979 & 0.061 & 0.814 & $15.926^{* *}$ & & \\
\hline \multirow[b]{2}{*}{ Team Performance } & $T P 1$ & 1.00 & - & 0.803 & - & \multirow[b]{2}{*}{0.784} & \multirow[b]{2}{*}{0.644} \\
\hline & $T P 2$ & 0.999 & 0.103 & 0.802 & $9.720 * *$ & & \\
\hline
\end{tabular}

Table 3. Squared inter-correlations between constructs.

\begin{tabular}{|c|c|c|c|c|c|c|}
\hline Inter-Correlations between Constructs & $\begin{array}{c}\text { Task } \\
\text { Interdependence }\end{array}$ & $\begin{array}{c}\text { Shared } \\
\text { Leadership }\end{array}$ & $\begin{array}{c}\text { Task-Oriented } \\
\text { Communication }\end{array}$ & $\begin{array}{l}\text { Relationship-Building } \\
\text { Communication }\end{array}$ & $\begin{array}{l}\text { Communication } \\
\text { Satisfaction }\end{array}$ & $\begin{array}{c}\text { Team } \\
\text { Performance }\end{array}$ \\
\hline Task Interdependence & - & & & & & \\
\hline Shared Leadership & 0.13 & _- & & & & \\
\hline Task-oriented Communication & 0.42 & 0.16 & _- & & & \\
\hline Relationship-building Communication & 0.18 & 0.23 & 0.18 & - & & \\
\hline Communication Satisfaction & 0.26 & 0.33 & 0.47 & 0.29 & _- & \\
\hline Team Performance & 0.31 & 0.28 & 0.38 & 0.31 & 0.50 & - \\
\hline
\end{tabular}




\section{Empirical Results}

SEM analysis was performed (see Figure 2), showing that the overall fitness of the model is appropriate for further analysis, $\chi^{2}=169.232(p<0.01), d f=90, \chi^{2} / d f=1.88, G F I=0.931, A G F I=0.895$, $N F I=0.941, N N F I=0.962, C F I=0.971, I F I=0.972$, and $S R M R=0.037$. In addition to the direct effects among the constructs shown in Figure 2, the sizes and significances of total effects combining direct and indirect effects are shown in Table 4.

While both task-oriented and relationship-building communications were significantly associated with task interdependence $(\beta=0.619, p<0.01 ; \beta=0.232, p<0.05$, respectively), the relationship with task-oriented communication was more than twice as strong as the connection with relationship-building communication. Although smaller, the relationship with task-oriented communication was still larger than the relationship with relationship-building communication when adding the indirect effects of task interdependence via shared leadership $(\beta=0.693, p<0.01 ; \beta=0.489$, $p<0.01$, respectively), supporting Hypothesis 1 .

Both task-oriented and relationship-building communications were significantly associated with shared leadership ( $\beta=0.170, p<0.05 ; \beta=0.332, p<0.01$, respectively), but the relationship with relationship-building communication was stronger than with task interdependence. The difference became larger when indirect effects were added to the comparison $(\beta=0.170, p<0.05 ; \beta=0.360$, $p<0.01$, respectively), supporting Hypothesis 3 . However, contrary to our expectation, no significant relationship was found between task-oriented and relationship-building communication $(\beta=0.163, n s)$, failing to support Hypothesis 7.

A significant relationship was found $(\beta=0.435, p<0.01)$, supporting Hypothesis 6 . Once pilots and controllers engaged in task-oriented and relationship-building communication and these are performed successfully, they led to communication satisfaction, and then finally to improved team performance. Task-oriented communication exerted much more influence $(\beta=0.537, p<0.01)$ on ACT-pilot team satisfaction than relationship-building communication $(\beta=0.204, p<0.01)$, supporting Hypothesis 8 . Since task-oriented communications are about the planned tasks at hand, it is natural for mechanical task-oriented communication to show stronger influence on communication satisfaction than the organic relationship-building communication.

However, in terms of the relationship between communication and team performance, only relationship-building communication had a significant direct effect $(\beta=0.167, p<0.05$ ), while task-oriented communication did not show significant association with performance $(\beta=0.137$, not significant). This result does not mean that the ACT-pilot team should regard relationship-building communication as superior to task-oriented communication. Since communication satisfaction exerted the highest direct influence on team performance $(\beta=0.344, p<0.01)$, and task-oriented communication had a large influence on communication satisfaction, having successful task-oriented communication between ACT-pilot teams indirectly affected team performance $(\beta=0.223, p<0.01)$. When adding both direct and indirect effects, task-oriented communication showed larger influence than relationship-building communication on team performance $(\beta=0.360, \beta=0.237, p<0.01$, respectively). In sum, both task-oriented and relationship-building communication affected team performance, supporting Hypothesis 9 and Hypothesis 10.

With regards to the relationship between task interdependence and team performance as well as the association between shared leadership and team performance, these two antecedents of ACT-pilot communication showed significant effects on team performance (task interdependence-team performance relationship: $\beta=0.116, p<0.05$; shared leadership-team performance relationship: $\beta=0.195, p<0.05)$, supporting Hypotheses 2 and 4 . Considering the total effects on team performance, among the measured constructs, task interdependence and shared leadership were largest $(\beta=0.662$, $p<0.01 ; \beta=0.626, p<0.01$, respectively). Finally, there was significant association between shared leadership and communication satisfaction $(\beta=0.282, p<0.01)$, supporting Hypothesis 5 . 
Table 4. Analysis of direct, indirect, and total causal effects among constructs.

\begin{tabular}{|c|c|c|c|c|}
\hline \multicolumn{2}{|l|}{ Causal Path } & \multirow{2}{*}{$\begin{array}{c}\text { Coef. } \\
0.435^{* *}\end{array}$} & \multirow{2}{*}{$\begin{array}{c}\text { Std. Coef. } \\
0.364\end{array}$} & \multirow{2}{*}{$\begin{array}{c}\text {-Value } \\
5.315\end{array}$} \\
\hline $\begin{array}{l}\text { Task Interdependence } \\
\rightarrow \text { Shared Leadership }\end{array}$ & Direct Effect & & & \\
\hline \multirow{3}{*}{$\begin{array}{l}\text { Task Interdependence } \\
\rightarrow \text { Task-oriented Communication }\end{array}$} & Direct Effect & $0.619^{* *}$ & 0.580 & 7.230 \\
\hline & Indirect Effect & $0.074^{* *}$ & 0.069 & 2.637 \\
\hline & Total Effect & $0.693^{* *}$ & 0.649 & 8.054 \\
\hline \multirow{3}{*}{$\begin{array}{l}\text { Task Interdependence } \\
\rightarrow \text { Relationship-building Communication }\end{array}$} & Direct Effect & 0.232 ** & 0.204 & 2.137 \\
\hline & Indirect Effect & $0.257^{* *}$ & 0.226 & 3.151 \\
\hline & Total Effect & $0.489 * *$ & 0.430 & 5.699 \\
\hline $\begin{array}{l}\text { Task Interdependence } \\
\rightarrow \text { Communication Satisfaction }\end{array}$ & Indirect Effect & $0.595^{* *}$ & 0.505 & 7.910 \\
\hline \multirow{3}{*}{$\begin{array}{l}\text { Task Interdependence } \\
\rightarrow \text { Team Performance }\end{array}$} & Direct Effect & $0.116^{* *}$ & 0.124 & 1.998 \\
\hline & Indirect Effect & $0.546^{* *}$ & 0.253 & 5.313 \\
\hline & Total Effect & $0.662 * *$ & 0.377 & 6.145 \\
\hline $\begin{array}{l}\text { Shared Leadership } \\
\rightarrow \text { Task-oriented Communication }\end{array}$ & Direct Effect & $0.170^{* *}$ & 0.190 & 2.890 \\
\hline \multirow{3}{*}{$\begin{array}{l}\text { Shared Leadership } \\
\rightarrow \text { Relationship-building Communication }\end{array}$} & Direct Effect & $0.332 * *$ & 0.348 & 4.730 \\
\hline & Indirect Effect & $0.028^{* *}$ & 0.029 & 1.333 \\
\hline & Total Effect & $0.360 * *$ & 0.377 & 5.228 \\
\hline \multirow{3}{*}{$\begin{array}{l}\text { Shared Leadership } \\
\rightarrow \text { Communication Satisfaction }\end{array}$} & Direct Effect & $0.282 * *$ & 0.286 & 4.624 \\
\hline & Indirect Effect & $0.165^{* *}$ & 0.167 & 3.784 \\
\hline & Total Effect & $0.447^{* *}$ & 0.453 & 7.395 \\
\hline $\begin{array}{l}\text { Shared Leadership } \rightarrow \text { Task-oriented } \\
\text { Communication }\end{array}$ & Direct Effect & $0.170^{* *}$ & 0.190 & 2.890 \\
\hline \multirow{3}{*}{$\begin{array}{l}\text { Shared Leadership } \\
\rightarrow \text { Relationship-building Communication }\end{array}$} & Direct Effect & $0.332 * *$ & 0.348 & 4.730 \\
\hline & Indirect Effect & $0.028^{* *}$ & 0.029 & 1.333 \\
\hline & Total Effect & $0.360 * *$ & 0.377 & 5.228 \\
\hline \multirow{3}{*}{$\begin{array}{l}\text { Shared Leadership } \\
\rightarrow \text { Communication Satisfaction }\end{array}$} & Direct Effect & $0.282 * *$ & 0.286 & 4.624 \\
\hline & Indirect Effect & $0.165^{* *}$ & 0.167 & 3.784 \\
\hline & Total Effect & $0.447^{* *}$ & 0.453 & 7.395 \\
\hline \multirow{3}{*}{$\begin{array}{l}\text { Shared Leadership } \\
\rightarrow \text { Team Performance }\end{array}$} & Direct Effect & $0.195^{* *}$ & 0.175 & 2.412 \\
\hline & Indirect Effect & $0.431^{* *}$ & 0.386 & 5.738 \\
\hline & Total Effect & $0.626^{* *}$ & 0.561 & 7.831 \\
\hline $\begin{array}{l}\text { Task-oriented Communication } \\
\rightarrow \text { Relationship-building Communication }\end{array}$ & Direct Effect & $0.163 * *$ & 0.153 & 1.476 \\
\hline \multirow{3}{*}{$\begin{array}{l}\text { Task-oriented Communication } \\
\rightarrow \text { Communication Satisfaction }\end{array}$} & Direct Effect & $0.537^{* *}$ & 0.486 & 6.877 \\
\hline & Indirect Effect & 0.033 ** & 0.030 & 1.435 \\
\hline & Total Effect & 0.570 ** & 0.516 & 7.128 \\
\hline \multirow{3}{*}{$\begin{array}{l}\text { Task-oriented Communication } \\
\rightarrow \text { Team Performance }\end{array}$} & Direct Effect & $0.137^{* *}$ & 0.131 & 1.377 \\
\hline & Indirect Effect & $0.223^{* *}$ & 0.213 & 3.827 \\
\hline & Total Effect & $0.360^{* *}$ & 0.344 & 3.993 \\
\hline $\begin{array}{l}\text { Relationship-building Communication } \\
\rightarrow \text { Communication Satisfaction }\end{array}$ & Direct Effect & $0.204^{* *}$ & 0.197 & 2.902 \\
\hline \multirow{3}{*}{$\begin{array}{l}\text { Relationship-building Communication } \\
\rightarrow \text { Team Performance }\end{array}$} & Direct Effect & $0.167^{* *}$ & 0.170 & 2.486 \\
\hline & Indirect Effect & $0.070^{* *}$ & 0.071 & 2.427 \\
\hline & Total Effect & $0.237^{* *}$ & 0.241 & 3.398 \\
\hline $\begin{array}{l}\text { Communication Satisfaction } \\
\rightarrow \text { Team Performance }\end{array}$ & Direct Effect & $0.344^{* *}$ & 0.363 & 4.085 \\
\hline
\end{tabular}




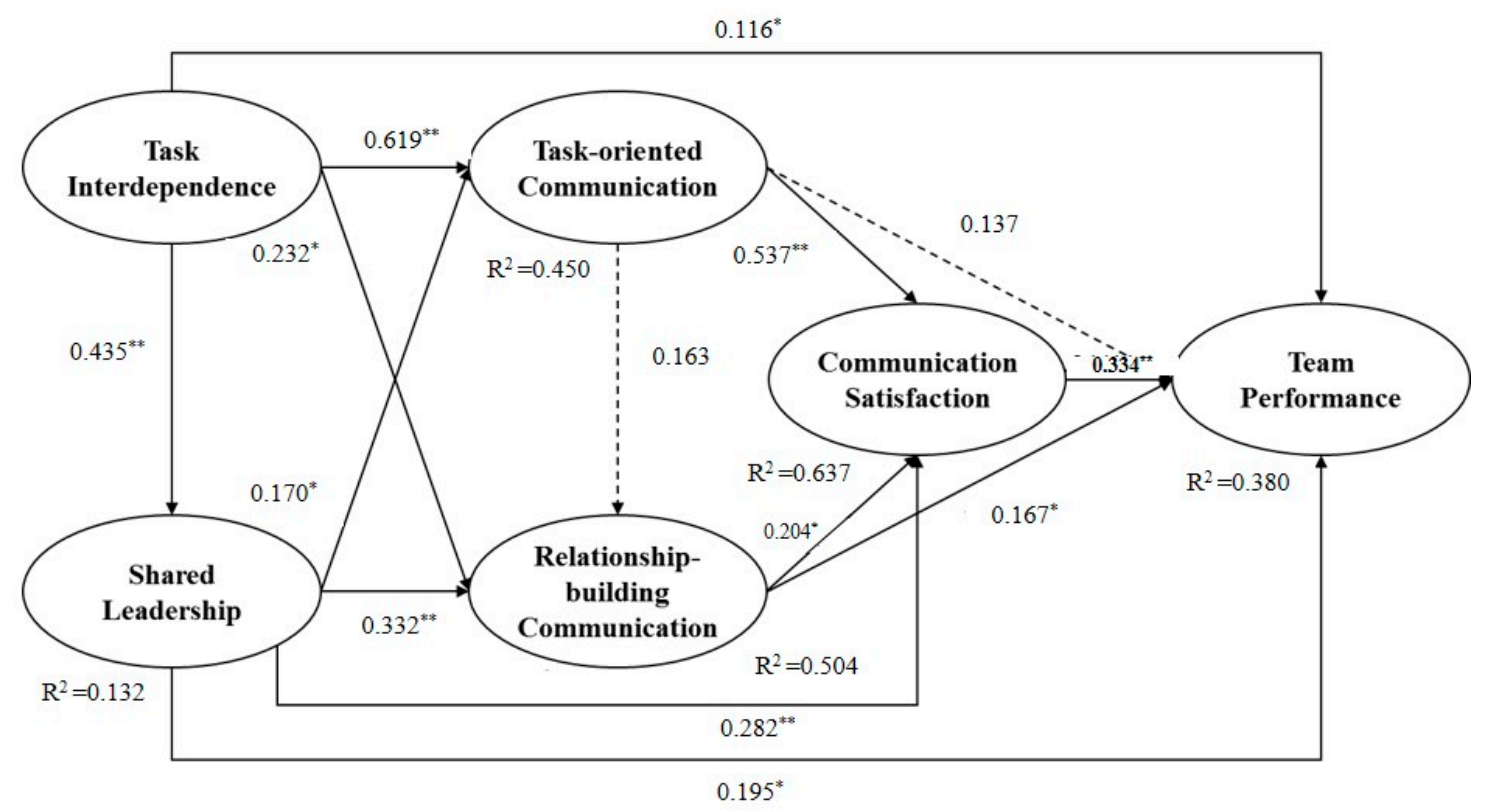

Figure 2. Causal relationships among constructs. Note: $\chi^{2}=169.232(p<0.01) ; d f=90 ; \chi^{2} / d f=1.88$; $\mathrm{GFI}=0.931 ; \mathrm{AGFI}=0.895 ; \mathrm{NFI}=0.941 ; \mathrm{NNFI}=0.962 ; \mathrm{CFI}=0.971 ; \mathrm{IFI}=0.972 ;$ and $\mathrm{SRMR}=0.037$. ${ }^{*} p<0.05 ;{ }^{* *} p<0.01$

\section{Discussion}

\subsection{Theoretical Implications}

First, it was confirmed that task interdependence exerted more influence than shared leadership on task-related communication. Considering the nature of task interdependence such that the interacting partners are relying on each other to achieve shared goals, partners will naturally focus on the communication related to successful collaboration. In aviation operations, pilots and controllers engage in different roles to complete the tasks at hand, naturally leading to the perception that each party cannot perform the tasks with the other party simply following. Under these circumstances, each interacting partner becomes highly dependent. Also, since communication between the ACT-pilot team takes place through the radio medium, the contents, clear transmission, and understanding of the communication become very important, which leads the team members to engage in much task-oriented or task-related communication.

Second, the current study investigated the sustainable relationship between relationship-building communication and the precursors in ACT-pilot teamwork. As mentioned above, shared leadership becomes more powerful when the interacting parties are cross-functional and thus lack hierarchical authority [31]. It is also reported that in a physically demanding environment, shared leadership affects communication among the workers which leads to relationship-building. As expected, the current study confirmed the hypothesis that shared leadership predicts relationship-building communication more than does task interdependence.

Finally, we confirmed the hypothesis comparing the degrees of relationship between each communication type and team performance. As expected, while the relationship between relationship-building communication and team performance was significant, the association between task-oriented communication and team performance was not. This result is likely due to the fact that team performance items measured overall perceived performance and efficiency of the team rather than specific performance scores. However, it still is interesting that the perceived task performance in a collaborating group is not directly influenced by technical ability but by relational capability. 


\subsection{Practical Implications}

Findings from our study may be helpful to controllers, pilots, and relevant parties involved in airline operation service. First, practitioners should emphasize sustainable relationship management in collaborative work groups, especially in work teams collaborating under constraints in time and space where workers have greater physical and mental difficulties in performing tasks than workers without such constraints. As measured in this study, task interdependence implies that each working partner does not have the entire knowledge and information needed to fulfill a successful task, thus all partners in work groups should depend on each other to accomplish assigned tasks [11]. To enhance task interdependence, each party in the collaborative group needs to understand the role as well as the working conditions of the other party. For example, Hindson [50] suggested a co-training and exchange program. Such training is expected to enhance collaborative work partners' recognition that without help and proper understanding of their colleagues the collaborative work task is not likely to be successfully achieved.

Second, from the finding that task-oriented communication directly improved communication satisfaction and indirectly increased team performance, we suggest that task-oriented communication needs to be enhanced in collaborative work groups. Previous reports and studies provide guidelines for effective ACT-pilot communication such as non-standard phraseology and effective listening/readback skills e.g., [7]. Thus, continuously focusing on these technical features will keep the chances of aviation accidents and incidents low.

Third, we found that relationship-building communication promoted communication satisfaction and sustainable performance. In this study, relationship-building communication is described as being courteous, professional, and attentive in communication. Therefore, when interacting with work partners, improving these qualities in communication is expected to increase task performance. Usually, flight attendants undergo thorough etiquette training because they serve passengers from different cultures [51]. Compared to flight attendants, the required etiquette may be less strict for pilots and controllers because they hardly encounter passengers and they use technical language during work. However, insufficient etiquette training for controllers and pilots may result in lowered task performance in flight which could increase the possibility of incidents or accidents.

\subsection{Directions for Future Research and Conclusions}

There are several drawbacks to this study. First, we selected task interdependence, shared leadership, task-oriented communication, relationship-building communication, and communication satisfaction as the variables that influence ACT-pilot team performance. Although these are representative and frequently applied variables for teamwork in the field of organizational studies, there could be many other situational, environmental, or unexpected variables influencing team performance. Therefore, examining team members' reactions in various industries toward other variables would be meaningful for future research.

Second, to elaborate the measurement of aviation team performance, it seems necessary to develop a new model that better reflects pilot and controller group characteristics. Hence, investigating the difference of bilateral influence among constructs that could exist during aviation operation will be important in drawing meaningful implications and useful information for practitioners.

Third, since the current study focuses on relational factors and performance, there is no concrete performance measures used in this study. Therefore, including both perceived and specific performance measures in the future would better capturing the group dynamics interaction and their outcomes.

Acknowledgments: This work was supported by a grant from Kyung Hee University in 2016 (KHU-20161701).

Author Contributions: Inwon Kang as a first Author, who created the research model and developed the survey, collected and distributed related data; Shin Han as a co-author, who analyzed the data and wrote a manuscript overall. Jiwon Lee, as a corresponding Author, who proofread a manuscript overall and enhanced the implications.

Conflicts of Interest: The authors declare no conflict of interest. 


\section{References}

1. Boies, K.; Fiset, J.; Gill, H. Communication and trust are key: Unlocking the relationship between leadership and team performance and creativity. Leadersh. Q. 2015, 26, 1080-1094. [CrossRef]

2. Coupland, N.; Giles, H.; Wiemann, J.M. Miscommunication and Problematic Talk; Sage: Newbury Park, CA, USA, 1991.

3. Catt, S.E.; Miller, D.S.; Hindi, N.M. Don't Misconstrue Communication Cues. Strat. Financ. 2005, 86, 50-55.

4. Hirokawa, R.Y. The role of communication in group decision-making efficacy: A task-contingency perspective. Small Group Res. 1990, 21, 190-204. [CrossRef]

5. Barshi, I.; Farris, M.C. Misunderstandings in ATC Communication: Language, Cognition, and Experimental Methodology; Ashgate Publishing, Ltd.: Farnham, UK, 2013.

6. Mosier, K.L.; Rettenmaier, P.; McDearmid, M.; Wilson, J.; Mak, S.; Raj, L.; Orasanu, J. Pilot-ATC Communication Conflicts: Implications for NextGen. Int. J. Aviat. Psychol. 2013, 23, 213-226. [CrossRef]

7. Airbus. Flight Operations Briefing Notes. Available online: http://skybrary.aero/bookshelf/books/194.pdf (accessed on 26 April 2014).

8. Morrow, D.; Rodvold, M. The Influence of ATC Message Length and Timing on Pilot Communication; NASA Ames Research Center: Moffett Field, CA, USA, 1993; pp. 1-26.

9. Whittaker, S.; Frohlich, D.; Daly-Jones, O. Informal workplace communication: What is it like and how might we support it? In Proceedings of the 1994 SIGCHI Conference on Human Factors in Computing Systems, Boston, MA, USA, 24-28 April 1994.

10. Morrow, D.; Lee, A.; Rodvold, M. Analysis of problems in routine controller-pilot communication. Int. J. Aviat. Psychol. 1993, 3, 285-302. [CrossRef]

11. Nielsen, T.M.; Bachrach, D.G.; Sundstrom, E.; Halfhill, T.R. Utility of OCB organizational citizenship behavior and group performance in a resource allocation framework. J. Manag. 2012, 38, 668-694.

12. Gladwell, M. Outliers: The Story of Success. In Development Research Group Policy Research Working Paper; Little, Brown and Company: New York, NY, USA, 2008; pp. 58-69.

13. Plane Crash Info. Causes of Fatal Accidents by Decade. Available online: http://www.planecrashinfo.com/ cause.htm (accessed on 27 April 2014).

14. Williams, E. Experimental comparisons of face-to-face and mediated communication: A review. Psychol. Bull. 1977, 84, 963-976. [CrossRef]

15. Habermas, J. What is universal pragmatics? In On the Pragmatics of Communication; Cooke, M., Ed.; MIT Press: Cambridge, MA, USA, 1976; pp. 21-104.

16. Froehle, C.M. Service personnel, technology, and their interaction in influencing customer satisfaction. Decis.'Sci. 2006, 37, 5-38. [CrossRef]

17. Diberardinis, J.; Tocci, J.A.; O’Brien, K. The Impact of Task-Oriented Communication and Visual Impairment on Competitive Groups. Group Organ. Manag. 1979, 4, 229-238. [CrossRef]

18. Jarvenpaa, S.L.; Leidner, D.E. Communication and trust in global virtual teams. J. Comput. Mediat. Comm. 1998. [CrossRef]

19. Giffords, E.D.; Calderon, O. Academic and Community Collaborations: An Exploration of Benefits, Barriers and Successes. Hum. Serv. Org. Manag. 2015, 39, 397-405. [CrossRef]

20. Kirwan, B.; Scaife, R.; Kennedy, R. Investigating complexity factors in UK air traffic management. Hum. Factors Aerosp. Saf. 2001, 1, 125-144.

21. Foushee, H.C.; Helrnreich, R.L. Group Interaction and Flight Crew Performance; Weiner, E.L., Nagel, D.C., Eds.; Academic Press: San Diego, CA, USA, 1988; pp. 189-227.

22. Jing, H.S.; Lu, P.J.; Yong, K.; Wang, H.C. The dragon in the cockpit: The faces of Chinese authoritarianism. Hum. Factors Aerosp. Saf. 2002, 2, 257-275.

23. Guzzo, R.A.; Shea, G.P. Group performance and intergroup relations in organizations. In Handbook of Industrial and Organizational Psychology; Dunnette, M.D., Hough, L.H., Eds.; Consulting Psychologists Press: Palo Alto, CA, USA, 1992; pp. 269-313.

24. Hoch, J.E.; Dulebohn, J.H. Shared leadership in enterprise resource planning and human resource management system implementation. Hum. Res. Manag. Rev. 2013, 23, 114-125. [CrossRef]

25. Rhoades, D.L.; Waguespack, B., Jr. Twenty years of service quality performance in the US airline industry. Manag. Serv. Qual. 2008, 18, 20-33. [CrossRef] 
26. Crawford, J.L.; Haaland, G.A. Predecisional information-seeking and subsequent conformity in the social influence process. J. Pers. Soc. Psychol. 1972, 23, 112-119. [CrossRef]

27. Molleman, E. Attitudes toward flexibility the role of task characteristics. Group Organ. Manag. 2009, 34, 241-268. [CrossRef]

28. Cao, Y.; Bunger, A.C.; Hoffman, J.; Robertson, H.A. Change Communication Strategies in Public Child Welfare Organizations: Engaging the Front Line. Hum. Serv. Org. Manag. 2016, 40, 37-50. [CrossRef]

29. Staples, D.S.; Webster, J. Exploring the effects of trust, task interdependence and verticalness on knowledge sharing in teams. Inform. Sys. J. 2008, 18, 617-640. [CrossRef]

30. Pearce, C.L.; Conger, J.A. Shared Leadership: Reframing the Hows and Whys of Leadership; Sage: Thousand Oaks, CA, USA, 2013.

31. Bligh, M.C.; Pearce, C.L.; Kohles, J.C. The importance of self-and shared leadership in team based knowledge work. J. Manag. Psychol. 2006, 21, 296-318. [CrossRef]

32. D'Innocenzo, L.; Mathieu, J.E.; Kukenberger, M.R. A meta-analysis of different forms of shared leadership-Team performance relations. J. Manag. 2016, 42, 1964-1991. [CrossRef]

33. Perry, M.L.; Pearce, C.L.; Sims, H.P., Jr. Empowered selling teams: How shared leadership can contribute to selling team outcomes. J. Pers. Sell. Sales Manag. 1999, 19, 35-52.

34. Carson, J.B.; Tesluk, P.E.; Marrone, J.A. Shared leadership in teams: An investigation of antecedent conditions and performance. Acad. Manag. J. 2007, 50, 1217-1234. [CrossRef]

35. Barry, D. Managing the bossless team: Lessons in distributed leadership. Organ. Dyn. 1991, 20, 31-47. [CrossRef]

36. Latane, B.; Williams, K.; Harkins, S. Many hands make light the work: The causes and consequences of social loafing. J. Pers. Soc. Psychol. 1979, 37, 822-832. [CrossRef]

37. Clampitt, P.G.; Downs, C.W. Employee perceptions of the relationship between communication and productivity: A field study. J. Bus. Commun. 1993, 30, 5-28. [CrossRef]

38. Pornsakulvanich, V.; Haridakis, P.; Rubin, A.M. The influence of dispositions and Internet motivation on online communication satisfaction and relationship closeness. Comput. Hum. Behav. 2008, 24, 2292-2310. [CrossRef]

39. Marshall, C.; Novick, D. Conversational effectiveness and multi-media communications. Inform. Technol. People 1995, 8, 54-79. [CrossRef]

40. Mount, D.J.; Back, K.J. A factor-analytic study of communication satisfaction in the lodging industry. J. Hosp. Tour. Res. 1999, 23, 401-418. [CrossRef]

41. Sun, W.; Xu, A.; Shang, Y. Transformational leadership, team climate, and team performance within the NPD team: Evidence from China. Asia. Pac. J. Manag. 2014, 31, 127-147. [CrossRef]

42. Bonini, D.; Jackson, A.; McDonald, N. Do I trust thee? An approach to understanding trust in the domain of air traffic control. In Proceedings of the 2011 International Conference on Human Interfaces in Control Rooms, Cockpits and Command Centers, Manchester, UK, 19-21 June 2001; IEEE Conference Publication: Piscataway, NJ, USA, 2011; pp. 104-109.

43. Hetty van Emmerik, I.J. It is not only mentoring: The combined influences of individual-level and team-level support on job performance. Career Dev. Int. 2008, 13, 575-593. [CrossRef]

44. Sperling, B.K.; Pritchett, A.R. Complementary information distribution to improve team performance in military helicopter operations: An experimental study. Int. J. Aviat. Psychol. 2011, 21, 375-396. [CrossRef]

45. Rosh, L.; Offermann, L.R.; Van Diest, R. Too close for comfort? Distinguishing between team intimacy and team cohesion. Hum. Resour. Manag. Rev. 2012, 22, 116-127. [CrossRef]

46. DeOrtentiis, S.; Summers, P.K.; Ammeter, J.P.; Douglas, A.C.; Ferris, R.G. Cohesion and satisfaction as mediators of the team trust-team effectiveness relationship: An interdependence theory perspective. Career Dev. Int. 2013, 18, 521-543. [CrossRef]

47. Hoch, J.; Pearce, C.; Welzel, L. Is the most effective team leadership shared? J. Pers. Psychol. 2010, 9, $105-116$. [CrossRef]

48. Hair, J.F.; Tatham, R.L.; Anderson, R.E.; Black, W. Multivariate Analysis; Prentice-Hall: Upper Saddle River, NJ, USA, 1998; pp. 207-219.

49. Podsakoff, P.M.; MacKenzie, S.B.; Lee, J.Y.; Podsakoff, N.P. Common method biases in behavioral research: A critical review of the literature and recommended remedies. J. Appl. Psychol. 2003, 88, 879-903. [CrossRef] [PubMed] 
50. Hindson, G. Overcoming the Corporate Culture Wall to Enhance Flight Safety and Efficiency; Training Report; ICAO: Montreal, QC, Canada, 2012; Volume 2, pp. 10-13.

51. Liang, S.C.; Hsieh, A.T. Individual's perception of career development and job burnout among flight attendants in Taiwan. Int. J. Aviat. Psychol. 2005, 15, 119-134. [CrossRef] 